\title{
Asymptomatic Plasmodium spp. infection in Tierralta, Colombia
}

\author{
Zulma Milena Cucunubá, Ángela Patricia Guerra', Sonia Judith Rahirant ${ }^{1}$, Jorge Alonso Rivera ${ }^{1}$, \\ Liliana Jazmín Cortés, Rubén Santiago Nicholls/ ${ }^{+}$
}

Grupo de Parasitología ${ }^{1}$ Grupo de Bioquímica y Biología Celular, Instituto Nacional de Salud, Avenida Calle 26 51-20, Bogotá DC, Colombia

With the aim of determining the prevalence of asymptomatic Plasmodium spp. infection by thick smear and PCR and its association with demographic and epidemiological characteristics in the village of Nuevo Tay, Tierralta, Córdoba, Colombia, a cross-sectional population study was carried out, using random probabilistic sampling. Venous blood samples were taken from 212 people on day 0 for thick smear and PCR. Clinical follow-up and thick smears were carried out on days 14 and 28. The prevalence of Plasmodium spp. infection was 17.9\% (38/212; 95\% CI: 12.5-23.3\%) and the prevalence of asymptomatic Plasmodium spp. infection was 14.6\% (31/212; 95\% CI: 9.6-19.6\%). Plasmodium vivax was found more frequently (20/31; 64.5\%) than Plasmodium falciparum (9/31; 29\%) and mixed infections (2/31; 6.5\%). A significantly higher prevalence of asymptomatic infection was found in men (19.30\%) than in women (9.18\%) (prevalence ratio: 2.10; 95\% CI: 1.01-4.34\%; $p=0.02$ ). People who developed symptoms had a significantly higher parasitemia on day 0 than those who remained asymptomatic, of $1,881.5 \pm 3,759$ versus $79 \pm$ $106.9(p=0.008)$. PCR detected 50\% more infections than the thick smears. The presence of asymptomatic Plasmodium spp. infection highlights the importance of carrying out active searches amongst asymptomatic populations residing in endemic areas.

Key words: malaria - Colombia - Plasmodium spp. - asymptomatic infection - PCR - thick smear

Malaria is an important public health problem worldwide and in Latin America (WHO 2005). In Colombia, 89,886 cases were officially notified in 2006, 59,867 (66.60\%) by Plasmodium vivax, 30,229 (32.28\%) by Plasmodium falciparum, $10(0,001 \%)$ by Plasmodium malariae and 992 (1,10\%) mixed infections (INS 2006).

Asymptomatic Plasmodium spp. infections are frequently found in hyperendemic regions in Africa (OwsusuAgyei et al. 2001). There is growing interest in ascertaining the role of asymptomatic Plasmodium spp. infection in South America (Coura et al. 2006). Studies carried out in the Amazon region of Brazil and Peru have confirmed that asymptomatic parasitemia occurs in the absence of intense transmission (Roper et al. 2000, Alves et al. 2002, Roshanravan et al. 2003, Marcano et al. 2004, Branch et al. 2005, Cerutti et al. 2007, Fugikaha et al. 2007).

One of the most important consequences of asymptomatic infection is that people do not seek medical attention or treatment and therefore they may become gametocyte carriers, contributing to the persistence of malaria transmission (Bousema et al. 2004, Alves et al. 2005). Besides, asymptomatic infection is also considered to be a risk factor for chronic anaemia (Verhoef et al. 2001).

\footnotetext{
Financial support: International Atomic Energy Agency (project RLA/6/055), Colombian Instituto Nacional de Salud (INS); ZMC was supported by Colciencias and INS (agreement No. 176-2006).

+ Corresponding author: rnichols@ins.gov.co

Received 17 April 2008

Accepted 10 November 2008
}

Few studies have been carried out in Colombia on asymptomatic Plasmodium spp. infection, most of them on the Pacific coast, one of the main endemic areas in Colombia, where $P$. falciparum is responsible for at least $80 \%$ of the cases. The prevalence of asymptomatic infection (day 0) found in these studies, using microscope examination, ranged between 0-33.1\% (Terrientes et al. 1994, Gautret et al. 1995, Gonzalez et al. 1997, Mendez et al. 2000, Osorio et al. 2004). A 21.6\% prevalence of asymptomatic infection was found in a study carried out on indigenous people from the Colombian Amazon region, where $P$. vivax is the predominant species (Coura et al. 2006). However, none of these studies included either patient follow-up or PCR testing.

The purpose of this study was to determine the prevalence of asymptomatic Plasmodium spp. infection in a village in Tierralta, Cordoba, by using microscope examination and PCR as diagnostic methods.

\section{SUBJECTS, MATERIALS AND METHODS}

Study area - The study was carried out from September-December 2006 in the village of Nuevo Tay, municipality of Tierralta, in the department of Cordoba; this village's coordinates are: $76^{\circ} 8^{\prime} 5.6^{\prime \prime} \mathrm{W}$ and $8^{\circ} 5^{\prime} 21.9^{\prime}$ ' $\mathrm{N}$ (Figure); its altitude is $5 \mathrm{~m}$ above sea level. Tierralta reported 13,940 cases of malaria in 2005 , accounting for $13.4 \%$ of the total number of cases reported in Colombia during that year (Pérez et al. 2008). Most of the cases, $60.7 \%$, occurred in males from the 15-19 years age group. The Annual Parasite Index in this municipality in 2005 was 304/1,000; the Annual Vivax Index 192/1,000 and the Annual Falciparum Index 106/1,000 (Perez et al. 2008). The main vector species in this area are Anopheles darlingi and Anopheles albimanus (Olano et al. 2001). 


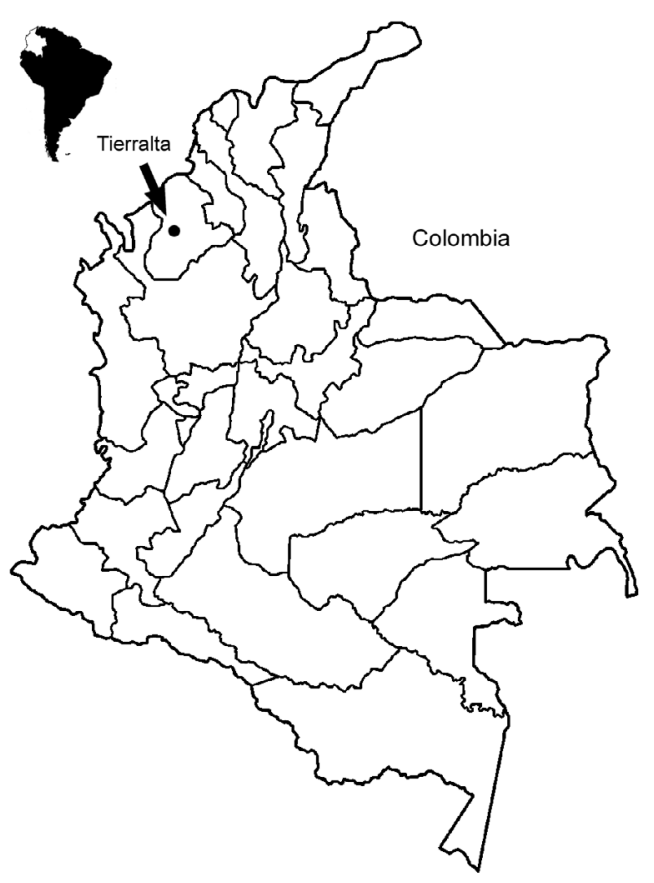

Map of the study area.

Study design - The study was carried out in three phases. A census of the whole village was performed during the first phase. Each inhabitant was registered with a consecutive number, including its name, age and gender. Houses' coordinates were recorded using an Etrex ${ }^{\mathrm{TM}}$ global positioning system, Ventura model. All the data was recorded in an MS Excel ${ }^{\mathrm{TM}}$ database. Random sampling, based on individuals, was performed during the second phase. Asymptomatic people were randomly selected for a survey including physical examination and blood sample collection on day 0 for detecting Plasmodium spp. infection by thick blood smear and PCR. During the third phase a thick blood smear and clinical follow-up of people examined on day 0 were done on days 14 and 28.

Census - One hundred and ninety-five houses were found, having a total of 1,062 inhabitants; 96 people were considered to be non-eligible for one of the following reasons: age less than two years, ongoing pregnancy, having presented signs and symptoms of malaria such as fever, headache, chills or malaise during the previous week, body temperature above $37.5^{\circ} \mathrm{C}$ and intending to change residence within the next two months; 966 people were considered eligible.

Sample size calculation and sampling - Based upon the results of previous studies, assuming an expected 5\% $\pm 3 \%$ prevalence with a $95 \%$ confidence level, a sample size of 168 was calculated. A possible $20 \%$ loss of patients during follow-up was considered; it was therefore decided to take a minimum of 200 samples. Simple random sampling was carried out using a random number table after allocating a number to each eligible person. Overall, 212 people were included for examination on day 0 .
Survey, physical examination and sample-taking Physicians held clinical interviews on day 0 . These included questions with a single, closed answer for demographic variables and history of malaria. A physical examination which included taking body temperature, blood pressure, respiratory rate and pulse was carried out. A $4 \mathrm{~mL}$ volume of venous blood was collected in a tube containing $5.3 \mathrm{mM}$ EDTA. The samples were kept at $4^{\circ} \mathrm{C}$ until they reached the laboratory for DNA extraction and PCR analysis. Simultaneously, a thick smear was taken for microscopy and microhematocrit analysis for determining the prevalence of anaemia, using the cutoff values to define anemia in people living at sea level (Stoltzfus \& Dreyfuss 1998).

Patient follow-up and treatment - All the individuals who were examined on day 0 were followed-up on days 14 and 28. A physician carried out interviews and took the thick smears. Asymptomatic patients with a positive thick smear on day 0 were followed-up during 14 days to ascertain whether asymptomatic Plasmodium spp. infections persisted or corresponded to the disease's incubation period. Those who developed symptoms were treated immediately and those who remained asymptomatic were treated on day 14. Treatment was prescribed according to the official Colombian regulations at the time of the study: patients with $P$. vivax received chloroquine and primaquine, while patients with P. falciparum received amodiaquine, sulfadoxine/pyrimethamine and primaquine (MS 2000).

Analysis by microscopy - Two thick smears were taken from each patient; blood sample taking, preparation and staining were done according to the procedures standardised by the Instituto Nacional de Salud's Parasitology Group (INS) (Mendoza et al. 2001). The thick smears were read by experienced malaria microscopists. The slides were read a second time at the national reference centre (Parasitology Group, National Reference Laboratory Division, INS); discordant results were evaluated by a third reader. The readers were not aware of the clinical records of the people studied or of the PCR results. Likewise, the persons who carried out the PCR processing of samples were unaware of the clinical records and of the thick smear results.

Extraction of parasite DNA and PCR amplification DNA was extracted from $300 \mu \mathrm{L}$ venous blood obtained on day 0 , using a Wizard genome DNA purification kit (Promega), following the manufacturer's recommendations. A first PCR reaction was done using genus-specific primers rPLU6 and rPLU5 following the amplification conditions described by Snounou et al. (1993). For the second reaction (nested PCR), we used speciesspecific primers rFAL1 and rFAL2, rVIV1 and rVIV2 and rMAL1 and rMAL2 for P. falciparum, $P$. vivax and $P$. malariae, respectively, and the protocol reported by Singh et al. (1999). Some minor modifications were: $1 \mathrm{U}$ Taq DNA polymerase (Promega) was used in the first amplification round whilst $2 \mathrm{mM} \mathrm{MgCl}$ in all reactions and 20 cycles were used to amplify $P$. vivax DNA in the second round. The products obtained in the nested PCR 
were submitted to $2 \%$ agarose gel electrophoresis and stained with ethidium bromide $(1 \mu \mathrm{g} / \mathrm{mL})$. The bands were visualised under ultraviolet light and analysed using One dScan ${ }^{\mathrm{TM}}$ software, version 3.1. Expected fragment sizes were: $205 \mathrm{bp}$ for $P$. falciparum, $120 \mathrm{bp}$ for $P$. vivax and $144 \mathrm{bp}$ for $P$. malariae.

Definition of asymptomatic infection - For the purposes of this study, asymptomatic Plasmodium spp. infection was defined as the detection by microscopy of asexual parasite stages of $P$. falciparum, $P$. vivax or $P$. malarie or of mixed infections in blood, which persisted for at least two weeks without causing any symptoms, or as the detection of parasite DNA by PCR on day 0 in people who remained asymptomatic during the follow-up period. Plasmodium ovale was not considered in this study since this species has not been reported in Colombia.

Statistical analysis - The population was characterised according to basic demographic variables such as age, gender, place of residence and time spent living in the area. The other variables of interest concerned having a history of malarial infections throughout the patient's whole life and during the last year, treatment received, infecting species during the last episode, history of transfusions, as well as basic vital variables, and microhematocrit, thick smear and PCR results. The database was recorded on MS Excel ${ }^{\mathrm{TM}} 2000$; data were analysed with EPI-info 6.04b and STATA ${ }^{\text {TM }} 7.0$ was used for determining the confidence intervals. The prevalence of asymptomatic Plasmodium spp. infection was described regarding the above variables and both uni and bivariate analyses were carried out using prevalence ratios; $\mathrm{p}<$ 0.05 values were considered to be significant.

Ethics - The study followed both the international and national standards on human experimentation, including the Helsinki Declaration (WMA 2000) and the national regulations (MS 1993), according to which this was an investigation having minimum risk for the patients. This study was approved by INS Ethics Committee (protocol number CTIN-023-05, approval 2nd June). After the participants had been interviewed, all of them received complete information about the study and agreed to participate in it by signing the informed consent forms. Adults, as well as the parents of all children below 18 years included in the study, were asked to sign an informed consent form. Children aged 7-17 were asked to sign an assent form besides the informed consent form signed by their parents.

Individuals suspect of having malaria (due to symptoms in the previous week) or having fever at day 0 , who were considered not eligible for the study, received medical assistance immediately, including a thick blood smear which was read on the same day. Those who had positive blood smears were treated as described previously.

\section{RESULTS}

The average age of the 212 individuals who participated in this study was 24.5 with a standard deviation of 18.1 (median: 18 years; range: 2-78 years). Thick smears were positive in 24 of 212 people $(11.3 \%$; $95 \%$ CI: 7.2-16.8\%), while PCR detected 35 positive samples
(16.5\%; 95\% CI: $11.5-22.9 \%)$; the difference was statistically significant $(\mathrm{p}<0.05)$. The Kappa index between the microscope readers was 0.92 (95\% CI: 0.74-1.31). A total of 38 cases of infection were found by either thick smear or PCR on day 0 . Seven of the 38 infected persons on day 0 developed symptoms of malaria during the 14 day follow-up; six of these seven patients had $P$. vivax and one $P$. falciparum. Therefore, the prevalence of Plasmodium spp. infection in the studied population was $17.9 \%$ (38/212; 95\% CI: $12.5-23.3 \%)$ and the prevalence of asymptomatic Plasmodium spp. infection was 14.6\% (31/212; 95\% CI: 9.6-19.6\%).

Amongst the asymptomatic infections, $P$. vivax predominated $(20 / 31 ; 64.5 \%)$ as compared to $P$. falciparum $(9 / 31 ; 29 \%)$ and mixed infections $(2 / 31 ; 6.5 \%)$. Of these 31 persons, 28 were positive by PCR and 19 by microscopy; however, three of these 19 were negative by PCR. Thus, PCR detected 50\% more infections than microscopy. The Table describes the most important demographic and epidemiological characteristics of all the people studied and compares them according to their asymptomatic infection status.

A significantly higher prevalence of asymptomatic Plasmodium spp. infection was found in males than in females (Table). Asymptomatic $P$. vivax infections predominated in males, with a 10:3 male:female (M:F) ratio. Likewise, asymptomatic P. falciparum infections predominated amongst males with a 5:4 M:F ratio while a 1:1 M:F ratio was observed for mixed infections. The mean number of malaria episodes in life was 2.78 in men and 2.56 in women, but the difference was not statistically significant $(\mathrm{p}=0.13)$.

The parasitemia in the asymptomatic cases did not vary significantly according to the infecting species: $P$. vivax infections had an average of $65 \pm 98$ parasites/ $\mu \mathrm{L}$ (range: $0-398$ ) as compared to $114.7 \pm 147$ for $P$. falciparum (range: $0-394)$. Twenty one $(60 \%)$ of the asymptomatic cases detected by microscopy or PCR were grouped into $75(38.4 \%)$ houses located in the central area of the village.

On day 0 , five of the seven patients who were symptomatic during the 14-day follow-up (71.4\%) had positive thick smears and all of them had a positive PCR. The cases who turned symptomatic between days 0 and 14 had an average age of $14 \pm 9.2$ years (median: 15 ; range: $2-24$ ), compared to $27 \pm 18.8$ (median: 22; range: $2-72$ ) in those who continued as asymptomatic $(p=0.08)$. Parasitemia at day 0 varied significantly according to the outcome of the infection during follow-up: people presenting symptoms had an average parasitemia of $1,881.5 \pm 3,759$ parasites/ $\mu \mathrm{L}$ compared to $79 \pm 106.9$ parasites $/ \mu \mathrm{L}$ in those who persisted in the asymptomatic state $(\mathrm{p}=0.008)$.

According to the results of the thick smears taken on day 0 , five of 24 positive people received treatment before day 14 because they presented symptoms during follow-up, 13 (nine with $P$. vivax and four with $P$. falciparum) cleared their parasitemia, six (four with $P$. vivax and two with $P$. falciparum) had a second positive thick smear on day 14 and their parasitemia increased in one case, decreased in four and did not change in one. 
TABLE

Comparison of exposure variables between asymptomatic Plasmodium spp. infected individuals and the rest of the studied population in Nuevo Tay

\begin{tabular}{|c|c|c|c|c|c|c|}
\hline Characteristics of exposure & $\begin{array}{l}\text { Asymptomatic } \\
\text { Infected } \\
n\end{array}$ & $\begin{array}{c}\text { Rest }^{a} \\
\mathrm{n}\end{array}$ & $\begin{array}{c}\text { Total } \\
\mathrm{n}\end{array}$ & $\begin{array}{c}\text { Prevalence }^{b} \\
\%\end{array}$ & $\begin{array}{c}\mathrm{PR} \\
(95 \% \mathrm{CI})\end{array}$ & $\mathrm{p}$ \\
\hline & 31 & 181 & 212 & & & \\
\hline \multicolumn{7}{|l|}{ Sex } \\
\hline Female & 9 & 89 & 98 & 9.18 & 1 & \\
\hline Male & 22 & 92 & 114 & 19.30 & $\begin{array}{c}2.10 \\
(1.01-4.34)\end{array}$ & 0.02 \\
\hline \multicolumn{7}{|l|}{ Quiartile age distribution (years) } \\
\hline$<\mathrm{Q}_{1}(2-11)$ & 6 & 53 & 59 & 10.17 & 1 & \\
\hline $\mathrm{Q}_{1}-\mathrm{Q}_{2}(12-19)$ & 9 & 44 & 53 & 16.98 & $\begin{array}{c}1.66 \\
(0.63-4.37)\end{array}$ & 0.21 \\
\hline $\mathrm{Q}_{2-} \mathrm{Q}_{3}(20-36)$ & 7 & 43 & 50 & 14.00 & $\begin{array}{c}1.37 \\
(0.49-3.83)\end{array}$ & 0.37 \\
\hline$>Q_{3}(37-78)$ & 9 & 41 & 50 & 18.00 & $\begin{array}{c}1.77 \\
(0.67-4.63)\end{array}$ & 0.18 \\
\hline $\begin{array}{l}\text { Years of residence in the village } \\
\text { mean (SD) }\end{array}$ & $11.6(6.9)$ & $10.1(6.7)$ & $10.3(6.8)$ & & & 0.33 \\
\hline \multicolumn{7}{|l|}{ Malaria episodes during life } \\
\hline Never & 4 & 40 & 44 & 9.09 & 1 & \\
\hline Once & 3 & 27 & 30 & 10.00 & $\begin{array}{c}1.10 \\
(0.26-4.56)\end{array}$ & 0.59 \\
\hline $2-5$ & 16 & 72 & 88 & 18.18 & $\begin{array}{c}2.00 \\
(0.71-5.62)\end{array}$ & 0.13 \\
\hline$>5$ & 8 & 42 & 50 & 16.00 & $\begin{array}{c}1.76 \\
(0.56-5.44)\end{array}$ & 0.24 \\
\hline
\end{tabular}

$a$ : this group includes seven infected symptomatic people and 174 non-infected asymptomatic people; $b$ : prevalence of asymptomatic Plasmodium infection; CI: confidence interval; PR: prevalence ratio; SD: standard deviation.

Two new cases of infection, both by $P$. vivax, were detected on day 14; they both remained asymptomatic during the 14 day follow-up until day 28. Besides, two adults, who had not been previously detected by thick blood smear or PCR, presented P. falciparum gametocytaemia on day 28.

The average microhematocrit value was $40.8 \% \pm$ $4.35 \%$; the values presented a close to normal distribution and prevalence of anaemia was $7.28 \%$ (15/206; $95 \%$ CI: 3.49-11.07\%). Prevalence of anaemia in people with asymptomatic Plasmodium spp. infection was $9.68 \%$ (3/31; 95\% CI: $2.04-25.75 \%)$, compared to $6.89 \%(12 / 174$; 95\% CI: $2.84-10.95 \%$ ) in non-infected people, but the difference was not statistically significant.

\section{DISCUSSION}

These results reveal the presence of asymptomatic Plasmodium spp. infection in a village in the Alto Sinú-Bajo Cauca region of Colombia. Previous studies in South America have been mainly carried out in the Amazon region, characterised as a tropical rain-forest (IDEAM 2000) according to Holdridge's life zones, with prevalences of Plasmodium spp. infection in asympto- matic people ranging between $2.4-49.5 \%$ in different populations (Roper et al. 2000, Alves et al. 2002, Roshanravan et al. 2003, Marcano et al. 2004). Most studies in Colombia have been carried out on the Pacific coast, a region classified as a very wet tropical rain-forest (IDEAM 2000). Since Tierralta is located at the interface between tropical rainforest, very wet pre-mountain rainforest and tropical dry forest (IDEAM 2000), the present study is the first one to report the presence of asymptomatic Plasmodium spp. infection in an area with different eco-epidemiological conditions to those of the Amazon region and the Pacific coast.

The population studied is relatively stable and has generally resided in the area for many years. The whole village is located on the banks of the Sinú River and the geographical distribution of asymptomatic Plasmodium infection cases showed a slight concentration in the central area of the village, while the rest of the cases were dispersed along the course of the river. The entomological variables which could explain this pattern remain to be studied.

$P$. vivax was the most prevalent infecting species in asymptomatic cases in this study, which is in accordance 
with the distribution of malaria species historically observed in this area. The significantly higher prevalence of asymptomatic Plasmodium spp. infection in men is probably related with an occupational risk factor for malaria infection. Men work in agricultural activities, in small plantations where mainly rice, plantain, yucca (cassava) and passion fruit are cultivated.

Clinical follow-up of patients is fundamental since the finding of asymptomatic parasitemia at any given moment could simply correspond to the incubation period or pre-pathogenic period and not to a real asymptomatic infection (Vinetz \& Gilman 2002), as occurred in seven cases in this study. The appearance of symptoms during follow-up was related to the parasitemia found on day 0 , as the patients who developed symptoms had a significantly higher average parasitemia than those who did not.

Negativization of the thick smear during the 14 day follow-up occurred in 13 of the 19 asymptomatic patients who had detectable parasitemia by thick smear on day 0 . Further studies should be carried out to establish if this could be explained by acquired immunological ability for self-limiting infection, as suggested by studies carried out in the Peruvian Amazon region (Roshanravan et al. 2003, Branch et al. 2005).

PCR detected $50 \%$ more infections than microscopy. However, three patients with a low parasitemia $(\leq 120$ parasites $(\mu \mathrm{L}$ ) by thick smear, two by $P$. falciparum and one by P.vivax, had a negative PCR result. Some studies have reported that PCR can occasionally give false negative results (Barker et al. 1994). A study carried out in Thailand found that the sensitivity and specificity of PCR as compared to thick smears by expert microscopists were $96 \%$ and $98 \%$, respectively, when parasitemias were greater than $500 / \mu \mathrm{L}$. However, with parasitemia levels below $100 / \mu \mathrm{L}$ the sensitivity decreases to $24 \%$ for both $P$. falciparum and $P$. vivax, suggesting that, in spite of PCR's multiple advantages, its efficiency depends on the quality and amount of DNA obtained from blood samples, the quality of the reagents and the use of optimum conditions during amplification (Coleman et al. 2006).

In spite of frequent associations between asymptomatic malaria and anaemia, no significant differences in hematocrit values were found between infected and non-infected people in this study.

One of the limitations of this study was the reduced sample size. Given the low number of cases of asymptomatic Plasmodium spp. infection found, most of the associations studied lacked strength, although this affects the precision but not the validity of the results. The fact that follow-up was only done by thick smears and not by PCR could also be regarded as a limitation. The PCR test used in this study did not allow for differentiation between asexual and sexual parasite stages, which is particularly important in P. falciparum infections. This should be considered for future studies since, strictly speaking, asymptomatic Plasmodium spp. infection can be defined as the detection by any technique of asexual parasite stages which persists for some time without causing any symptoms. Therefore, the prevalence of asymptomatic Plasmodium spp. infection, as determined by the PCR results, could have been overestimated in this study since people harboring only gametocytes gave a positive PCR result. A reverse-transcription PCR technique (RT-PCR) has been developed for allowing differentiation between asexual and sexual stages (Babiker et al. 1999).

The main conclusions of this study were that asymptomatic $P$. vivax and $P$. falciparum infections do exist in the Alto Sinú-Bajo Cauca region of Colombia, with $P$. vivax accounting for $64.5 \%$ of asymptomatic infections, that PCR detected 50\% more infections than microscopy, that men are at a greater risk of having asymptomatic Plasmodium spp. infections than women, and that people who developed symptoms had a significantly higher parasitemia on day 0 than those who remained asymptomatic throughout the follow-up period.

Studies carried out in Brazil and Peru suggest that infected asymptomatic patients could form the basis for continuing malaria endemicity in the Amazon region (Roshanravan et al. 2003). Further studies are needed to establish the potential role of infected asymptomatic people in the transmission of malaria in Nuevo Tay and in this malaria-endemic region of Colombia, as this could have important implications for the malaria surveillance and control measures.

PCR has a significantly higher detection capacity, making it useful for epidemiological studies, but, given their low cost and ease, thick smears are more suitable for carrying active search for asymptomatic infections. Further studies are needed, which should include entomological aspects, genotyping of asexual and sexual parasites and evaluating the immune response, for a better understanding of the asymptomatic Plasmodium spp. infections and their contribution to the dynamics of malaria transmission and to the incidence of symptomatic infections.

\section{ACKNOWLEDGEMENTS}

To A. Knudson, for her consultancy, to M. Suárez-Mutis, for her critical review of the manuscript, to A. Arévalo and S. Barrera, for their help with sample-taking, to J.L. Sierra, E. Hernández, D. Vargas (microscopists), M.L. Peña, C. Usta, the community of Nuevo Tay and their leaders: M. Hernández, T. Hernández and H. Pitalúa, for their help during the field study, to J. Garry, for the translation of this manuscript, and to the reviewers, whose names we shall never know, for their valuable time and comments which helped us to significantly improve this manuscript.

\section{REFERENCES}

Alves FP, Durlacher RR, Menezes MJ, Krieger H, Silva LH, Camargo EP 2002. High prevalence of asymptomatic Plasmodium vivax and Plasmodium falciparum infections in native Amazonian populations. Am J Trop Med Hyg 66: 641-648.

Alves FP, Gil LH, Marrelli MT, Ribolla PE, Camargo EP, Da Silva LH 2005. Asymptomatic carriers of Plasmodium spp. as infection source for malaria vector mosquitoes in the Brazilian Amazon. $J$ Med Entomol 42: 777-779.

Babiker HA, Abdel-Wahab A, Ahmed S, Suleiman S, RanfordCartwright L, Carter R, Walliker D 1999. Detection of low level Plasmodium falciparum gametocytes using reverse transcriptase polymerase chain reaction. Mol Biochem Parasitol 99: 143-148.

Barker RH Jr, Banchongaksorn T, Courval JM, Suwonkerd W, Rimwungtragoon K, Wirth DF 1994. Plasmodium falciparum 
and $P$. vivax: factors affecting sensitivity and specificity of PCRbased diagnosis of malaria. Exp Parasitol 79: 41-49.

Bousema JT, Gouagna LC, Drakeley CJ, Meutstege AM, Okech BA, Akim IN, Beier JC, Githure JI, Sauerwein RW 2004. P. falciparum gametocyte carriage in asymptomatic children in western Kenya. Malar J 3: 18.

Branch O, Casapia WM, Gamboa DV, Hernandez JN, Alava FF, Roncal N, Alvarez E, Perez EJ, Gotuzzo E 2005. Clustered local transmission and asymptomatic Plasmodium falciparum and Plasmodium vivax malaria infections in a recently emerged, hypoendemic Peruvian Amazon community. Malar J 4: 27.

Cerutti C Jr, Boulos M, Coutinho AF, Hatab Mdo C, Falqueto A, Rezende HR, Duarte AM, Collins W, Malafronte RS 2007. Epidemiologic aspects of the malaria transmission cycle in an area of very low incidence in Brazil. Malar J 6: 33.

Coleman RE, Sattabongkot J, Promstaporm S, Maneechai N, Tippayachai B, Kengluecha A, Rachapaew N, Zollner G, Miller RS, Vaughan JA, Thimasarn K, Khuntirat B 2006. Comparison of PCR and microscopy for the detection of asymptomatic malaria in a Plasmodium falciparum/vivax endemic area in Thailand. Malar J 5: 121.

Coura JR, Suárez-Mutis M, Ladeia-Andrade S 2006. A new challenge for malaria control in Brazil: asymptomatic Plasmodium infection-a review. Mem Inst Oswaldo Cruz 101: 229-237.

Fugikaha E, Fornazari PA, Penhalbel R de S, Lorenzetti A, Maroso RD, Amoras JT, Saraiva AS, Silva RU, Bonini-Domingos CR, Mattos LC, Rossit AR, Cavasini CE, Machado RL 2007. Molecular screening of Plasmodium spp. asymptomatic carriers among transfusion centers from Brazilian Amazon region. Rev Inst Med Trop Sao Paulo 49: 1-4.

Gautret P, Barreto M, Méndez F, Zorrilla G, Carrasquilla G 1995. High prevalence of malaria in a village of the Colombian Pacific coast. Mem Inst Oswaldo Cruz 90: 559-560.

González JM, Olano V, Vergara J, Arévalo-Herrera M, Carrasquilla G, Herrera S, López JA 1997. Unstable, low-level transmission of malaria on the Colombian Pacific Coast. Ann Trop Med Parasitol 91: 349-358.

IDEAM - Instituto de Hidrología, Meteorología y Estudios Medioambientales 2000. Bogotá: Zonas de vida de Holdridge. Available from: http://www.ideam.gov.co/atlas/mecosis.htm.

INS - Instituto Nacional de Salud 2006. Bogotá: Informe Vigilancia Epidemiológica de las Enfermedades Transmitidas por Vectores 2006. Available from: http://www.ins.gov.co/pdf/vcsp/ Tablas/2006/2006_semana_52.pdf.

Marcano TJ, Morgado A, Tosta CE, Coura JR 2004. Cross-sectional study defines difference in malaria morbidity in two Yanomami communities on Amazonian boundary between Brazil and Venezuela. Mem Inst Oswaldo Cruz 99: 369-376.

Mendez F, Carrasquilla G, Muñoz A 2000. Risk factors associated with malaria infection in an urban setting. Trans $R$ Soc Trop Med Hyg 94: 367-371.

Mendoza NM, Jaramillo CA, Guhl F, Padilla JC, Rentería MC 2001. Malaria diagnosis by nested PCR. Biomédica 21: 320-327.

MS - Ministerio de Salud 1993. Bogotá: Normas científicas, técnicas y administrativas para la investigación en salud. Resolución No. 008430 de 1993. Available from: http://www.minproteccionsocial. gov.co/VBeContent/NewsDetail.asp?ID=10287\&IDCompany=3.
MS - Ministerio de Salud 2000. Guía de atención de la malaria. Resolución No. 0412 de Bogotá, Colombia 2000. Available at http:// medicosgeneralescolombianos.com/Malaria.htm.

Olano VA, Brochero HL, Sáenz R, Quiñones ML, Molina JA 2001. Mapas preliminares de la distribución de especies de Anopheles vectores de malaria en Colombia. Biomédica 21: 402-408.

Osorio L, Todd J, Bradley D 2004. Absence of asymptomatic malaria in schoolchildren of Quibdó, Chocó. Biomédica 24: 13-19.

Owusu-Agyei S, Koram KA, Baird JK, Utz GC, Binka FN, Nkrumah FK, Fryauff DJ, Hoffman SL 2001. Incidence of symptomatic and asymptomatic Plasmodium falciparum infection following curative therapy in adult residents of Northern Ghana. Am J Trop Med Hyg 65: 197-203.

Pérez MA, Cortés LJ, Guerra AP, Knudson A, Usta C, Nicholls RS 2008. Eficacia de la combinación amodiaquina más sulfadoxina pirimetamina y de la cloroquina para el tratamiento del paludismo en Córdoba, Colombia, 2006. Biomédica 28: 148-159.

Roper MH, Torres RS, Goicochea CG, Andersen EM, Guarda JS, Calampa C, Hightower AW, Magill AJ 2000. The epidemiology of malaria in an epidemic area of the Peruvian Amazon. Am J Trop Med Hyg 62: 247-256.

Roshanravan B, Kari E, Gilman RH, Cabrera L, Lee E, Metcalfe J, Calderon M, Lescano AG, Montenegro SH, Calampa C, Vinetz JM 2003. Endemic malaria in the Peruvian Amazon region of Iquitos. Am J Trop Med Hyg 69: 45-52.

Singh B, Bobogare A, Cox-Singh J, Snounou G, Abdullah MS, Rahman HA 1999. A genus and species-specific nested polymerase chain reaction malaria detection assay for epidemiologic studies. Am J Trop Med Hyg 60: 687-692.

Snounou G, Viriyakosol S, Zhu XP, Jarra W, Pinheiro L, do Rosario VE, Thaithong S, Brown KN 1993. High sensitivity of detection of human malaria parasites by the use of nested polymerase chain reaction. Mol Biochem Parasitol 61: 315-320.

Stoltzfus RJ, Dreyfuss ML 1998. Guidelines for the use of iron supplements to prevent and treat iron deficiency anemia. International Nutritional Anemia Consultative Group (INACG), World Health Organization (WHO), United Nations Children's Fund (UNICEF), p. 4, Available from: http://www.helid.desastres.net/ gsd12/tmp/export/who/h0224e.pdf.

Terrientes ZI, Kramer K, Herrera MA, Chang SP 1994. Naturally acquired antibodies against the major merozoite surface coat protein (MSP-1) of Plasmodium falciparum acquired by residents in an endemic area of Colombia. Mem Inst Oswaldo Cruz 89: 55-61.

Verhoef H, West CE, Ndeto P, Burema J, Beguin Y, Kok FJ 2001. Serum transferrin receptor concentration indicates increased erythropoiesis in Kenyan children with asymptomatic malaria. Am J Clin Nutr 74: 767-775.

Vinetz JM, Gilman RH 2002. Asymptomatic Plasmodium parasitemia and the ecology of malaria transmission. Am J Trop Med Hyg 66: 639-640.

WHO - World Health Organization 2005. Geneva: World Malaria Report: Global Malaria situation. Available from: http://www.rbm. who.int/wmr2005/html/1-1.htm.

WMA - World Medical Association 2000. Declaration of Helsinki. Ethical principles for medical research involving human subjects. Last revision: 52nd WMA General Assembly, Edinburgh (Scotland), 2000. Available from: http://www.wma.net/e/policy/b3.htm. 